\title{
Characteristics of fast food consumption among adolescents
}

\author{
Akmaral Baspakova $^{1,2}$, Ainur Zinalieva ${ }^{1}$, Anara Abitova ${ }^{1}$ and Yeltay Rakhmanov ${ }^{3,4}$ \\ ${ }^{1}$ West Kazakhstan Marat Ospanov Medical University, Aktobe, Kazakhstan, \\ ${ }^{2}$ Center for Preventive Medicine, Aktobe, Kazakhstan, \\ ${ }^{3}$ The University of L'Aquila, L'Aquila, Italy and \\ ${ }^{4}$ MAGI-International Institute of diagnostics and research of genetic and rare disorders, Rovereto, Italy
}

\section{Abstract}

Special attention is paid to healthy eating in order to promote the health of children and adolescents. Eating habits are formed in childhood, respectively, a child who has eaten unhealthy food, including fast food, is at additional risk of noncommunicable diseases. Fast food is convenient and made to meet the tastes of consumers through the use of salt, sugar and fat. In addition, some ingredients can cause salience and physiological reactions that contribute to weight gain.

Improper nutrition of children and adolescents, non-compliance with the daily diet and the use of fast food products can lead to some diseases of the gastrointestinal tract, respiratory tract, as well as bronchial asthma, some endocrinological diseases. Therefore, the purpose of our research work was to determine the frequency of fast food consumption by adolescents in Aktobe, Republic of Kazakhstan.

The study was approved by the Local ethical Commission of the West Kazakhstan Marat Ospanov Medical University of Aktobe, Republic of Kazakhstan (№2 from 30.01.2018). By applying the questionnaire of the method was conducted experimentally controlled studies. The study involved 209 adolescents aged 15-18 years. Factors such as age and health were controlled. The primary data were analyzed using the McNemar's test, the open responses were coded, and the data were analyzed using SPSS Statistical Version 25.

$36.8 \%$ of the respondents consume fast food a couple times a week, $48.8 \%$ consume it once a week, and the remaining $14.3 \%$ consume the mentioned food several times a month. Before buying food, it was found that those who took care of food's nutritional value were $47.8 \%$, and $52.1 \%$ did not care about it. After having been informed of the dangers of fast food that the consumption of fast food leads to obesity, comparative differences were found in the results, respondents that answered "no" attained 5,26\%, $p=0.0001$ (odds ratio $[\mathrm{OR}]$ and $95 \%$ confidence interval $[\mathrm{CI}]]: 40[36,6-44,3])$. Healthy education programme offered to the adolescents led to the comparative difference in previous data to $5.9 \%$ in respondents who liked fast food and intended to continue taking on $\mathrm{p}=0.0001$ (OR and $95 \% \mathrm{CI}: 33,3$ [31,9-36,2]). After having attended the seminar on healthy eating, the number of respondents who liked and intended to continue consuming French fries and chips were decreased to $3.17 \%$, relative differences were obtained before retrieving data $\mathrm{p}=0.0001(\mathrm{OR}$ and $95 \%$ CI: $20.0[18,6-22.9])$.

Teenagers quite often use fast food and the majority of respondents visit fast food cafes, without thinking that poor nutrition is one of the factors of noncommunicable diseases and obesity among teenagers.

\section{Conflict of Interest}

There is no conflict of interest 